\title{
Effects of surface-finishing protocols on the roughness, color change, and translucency of different ceramic systems
}

\author{
Coşkun Akar, Gülcan ; Pekkan, Gürel ; Çal, Ebru ; Eskitaşçığlu, Gürcan ; Òzcan, Mutlu
}

\begin{abstract}
STATEMENT OF PROBLEM Surface-finishing protocols have a mechanical impact on ceramic surfaces that could eventually affect surface topography and light scattering. An optimum protocol is needed to avoid damaging the optical properties of ceramics. PURPOSE The purpose of this study was to determine the effects of different surface-finishing protocols on the surface roughness, color change, and translucency of ceramic and metal ceramic restorations. MATERIAL AND METHODS Standardized disk-shaped specimens $(1.5 \times 10 \mathrm{~mm}$, $\mathrm{n}=128$ ) were fabricated from 3 different ceramic core materials (aluminum oxide [Al2O3]-AL, zirconium oxide [ZrO2]-ZR, lithium disilicate [Li2Si2O5]-LIT), veneered $(\mathrm{V})$ with dentin ceramics $(\mathrm{n}=32$ per group), and placed in the following groups: ALV, ZRV, and LITV. The metal ceramic group acted as the control $(\mathrm{n}=32)$. Four different surface-finishing methods were tested. Airborne-particle abrasion with $50 \mu \mathrm{m} \mathrm{Al} 2 \mathrm{O} 3$, polishing with adjustment kit, polishing with adjustment kit plus diamond polishing paste, and autoglazing ( $\mathrm{n}=8$ subgroup) were applied on the veneering ceramics. The specimens were analyzed with a profilometer for surface roughness, and color change and translucency were measured with a clinical spectrophotometer. Statistical analyses were performed with 1-way ANOVA and the Tukey honest significant difference tests $(\alpha=.05)$. RESULTS Specimens treated with the airborne particle abrasion method showed significantly higher mean profilometer for surface roughness values in all groups $(\mathrm{P}<.05)$. The polishing with adjustment kit and autoglazing methods revealed statistically similar surface roughness values in all groups $(\mathrm{P}>.05)$. With the diamond polishing paste method, lower surface roughness values were achieved in the ZRV and metal ceramic groups acted as the control groups. Different surface-finishing methods affected the color change of the ceramic systems, except for ZRV. Surface-finishing protocols significantly affected the translucency values of the ALV, LITV, and metal ceramic groups $(\mathrm{P}<.05)$. CONCLUSIONS No single surface-finishing protocol can be recommended to obtain the smoothest surface and the least color change without affecting translucency for the ceramics tested. The airborne-particle abrasion protocol created rougher surfaces and decreased translucency, and color change in zirconia was not affected by the finishing protocols.
\end{abstract}

DOI: https://doi.org/10.1016/j.prosdent.2013.09.033

Posted at the Zurich Open Repository and Archive, University of Zurich

ZORA URL: https://doi.org/10.5167/uzh-100701

Journal Article

Accepted Version

Originally published at:

Coşkun Akar, Gülcan; Pekkan, Gürel; Çal, Ebru; Eskitaşçığlu, Gürcan; Özcan, Mutlu (2014). Effects of surfacefinishing protocols on the roughness, color change, and translucency of different ceramic systems. Journal of Prosthetic Dentistry, 112(2):314-321.

DOI: https://doi.org/10.1016/j.prosdent.2013.09.033 


\section{Effects of finishing methods on surface roughness, color change and translucency of different ceramic systems}

\section{Gülcan Coşkun Akar ${ }^{a}$, Gurel Pekkan ${ }^{b}$, Ebru Çal $^{c}$, Gürcan Eskitaşçıŏlu ${ }^{d}$, Mutlu Özcan ${ }^{e}$}

${ }^{\mathrm{a}}$ Ege University, Atatürk Medical Technology Vocational Training School, Bornova, 35100 Izmir, Turkey.

${ }^{\mathbf{b}}$ Dumlupinar University, Faculty of Dentistry, Tavsanli Yolu 10. Km., 43270 Kutahya, Turkey.

${ }^{\mathbf{c}}$ Ege University, Faculty of Dentistry, Department of Prosthodontics, Bornova, 35100 Izmir, Turkey.

${ }^{\mathbf{d} Y u z u n c u}$ Yil University, Faculty of Dentistry, Department of Prosthodontics, 65080 Van, Turkey.

${ }^{\mathrm{e}}$ University of Zurich, Center for Dental and Oral Medicine, Dental Materials Unit, Clinic for Fixed and Removable Prosthodontics and Dental Materials Science, Plattenstrasse 11, CH8032, Zurich, Switzerland.

\section{Corresponding author:}

Gürel PEKKAN, Assoc. Prof. Dr.

Dumlupinar University, Faculty of Dentistry

Department of Prosthodontics, 43270, Kutahya, TURKEY

Tel : +90-274-265 2031 (3007); Fax $\quad$ : +90-274-265 2056.

E-mail : gurelp@gmail.com 


\title{
Effects of surface finishing protocols on roughness, color change and translucency of different ceramic systems
}

\begin{abstract}
Statement of problem. Surface finishing protocols have a mechanical impact on ceramic surfaces that could eventually affect the surface topography and light scattering. An optimum protocol is needed not to sacrifice from optical properties of ceramics.

Purpose. The purpose of this study was to determine the effects of different surface finishing protocols on the surface roughness, color change and translucency of all-ceramic and metalceramic restorations.
\end{abstract}

Materials and methods. Standardized disc-shaped specimens $(1.5 \mathrm{~mm}$ x $10 \mathrm{~mm}, \mathrm{~N}=128)$ were fabricated using three different all-ceramic core materials $\left(\mathrm{Al}_{2} \mathrm{O}_{3}-\mathrm{AL}, \mathrm{ZrO}_{2}-\mathrm{ZR}\right.$, $\mathrm{Li}_{2} \mathrm{Si}_{2} \mathrm{O}_{5}$-LIT) materials and veneered (V) with dentin ceramics ( $\mathrm{n}=32$ per group) constituting the following groups: ALV, ZRV, LITV. Metal-ceramic group acted as the control (MC) $(n=32)$. Four different surface finishing methods were tested: Air-borne particle abrasion (AB) with $50 \mu \mathrm{m} \mathrm{Al}_{2} \mathrm{O}_{3}$, polishing with adjustment kit (PK), polishing with adjustment kit + diamond polishing paste (DP) and autoglazing (AG) ( $n=8$ subgroup) were applied on the veneering ceramics. The specimens were analyzed with a profilometer for surface roughness (Ra) and colour change $(\Delta \mathrm{E})$ and translucency (TP) were measured using a clinical spectrophotometer. The results were statistically analyzed using one-way ANOVA with Bonferronni corrections and Dunnett T3 tests $(\alpha=.05)$.

Results. Specimens treated with AB method showed significantly higher mean Ra values in all groups $(P<.05)$ followed by PK, DP, and AG methods. Different surface finishing methods affected the color change $(\Delta \mathrm{E})$ of the ceramic systems, except for ZRV. The highest TP values 
were observed after DP protocol, followed by AG, PK and AB. Surface finishing protocols did not show significant effect on TP $(P>.05)$, except for ALV.

Conclusions. One general surface finishing protocol to obtain the smoothest surface and the least colour change without affecting translucency cannot be recommended for all-ceramics tested. $\mathrm{AB}$ protocol created rougher surfaces and decreased translucency, and colour change in zirconia was not affected from finishing protocols.

CLINICAL IMPLICATIONS: Air-borne particle abrasion, polishing kits with and without polishing paste or autoglaze should be used accordingly depending on the all-ceramic type. For all ceramic types, the smoothest surfaces could be obtained after autoglazing. Surface finishing protocols significantly affect the translucency in alumina-based ceramics and also slightly change the translucency in zirconia-based and lithium disilicate-based ceramics.

Keywords: All-ceramics; Color change; Metal ceramic; Surface Roughness; Translucency; Zirconia 


\section{INTRODUCTION}

Matching the color of restorations to natural dentition in dentistry is often a clinical challenge. ${ }^{1}$ Besides clinical difficulties in shade matching, variations in optical characteristics of ceramics add to the problem of color control and final esthetic outcome. ${ }^{2,3}$ Ceramic types that can be easily polished and have hardness values less than enamel are desired to minimize the wear on the antagonist enamel. ${ }^{3}$ Natural glaze is a vitrified porcelain layer that forms on the surface of the porcelain, containing a glass phase when the porcelain is heated to the glazing temperature for the specified time according to the manusfacturer. ${ }^{4}$ This layer may be deteriorated by clinical adjustment of the final restoration resulting in rough surface resembling a pretreated surface texture..$^{4-7}$ Polishing have been shown to improve structural resistance to withstand oral conditions, and ensure optical characteristics of the restoration. ${ }^{8-10}$

Mismatch of translucency and color of the core and veneering system in a ceramic system with that of natural enamel that has inherent translucency can be considered a failure. ${ }^{11-18}$ The translucency of tooth-coloured restorative materials has usually been determined with the translucency parameter (TP). ${ }^{16,19}$ Ceramic translucency and color can be affected by many properties, including ceramic thickness, crystalline structure, number of ceramic firings, veneering technique, repeated ceramic staining cycles, grain size, pigments, number, size and distribution of defects, and porosity. ${ }^{20-26}$

The wide-spread clinical use of metal-ceramic restorations is mainly due to its highly predictable strength and reasonable esthetics. The drawback of such restorations is increased light reflectivity due to opaque porcelain layer. ${ }^{27,28}$ All-ceramic crowns permit greater light transmission through the crown and can mimic natural tooth appearance in terms of color, surface texture, and translucency. ${ }^{29-31}$ Nevertheless, variations in translucency in core material in a restoration may influence the final optical outcome. ${ }^{15,32}$ Core ceramics with high opacity 
are often used to mask the discolored substrates using the least amount of restoration thickness. ${ }^{16,30,33}$

Accurate and reliable color assessment is a prerequisite for successful esthetic outcome. While subjective and qualitative methods, i.e., shade guides and photographic methods lead to unpredictable results, electronic intraoral devices such as colorimeters and spectrophometers can objectively detect color differences. ${ }^{18,34-36}$ These high-precision devices can metrically deliver consistent results using the CIE (Commision International de l'Eclairage [illumination]) $\mathrm{L}^{*} \mathrm{a}^{*} \mathrm{~b}{ }^{*}$ system. ${ }^{37,38}$ In the widely-recognized CIE L*a*b* color system, the location of the particular shade in the color space is defined by 3 coordinates, $\mathrm{L}^{*} \mathrm{a}^{*} \mathrm{~b}^{*}$, where $\mathrm{L}^{*}$ describes a color due to the lightness of the object being assessed, a* values are the chromaticity coordinates in the red-green axis, and $b^{*}$ in the yellow-blue axis. The total color difference between 2 objects is described by $\Delta \mathrm{E}$. Although it indicates a color difference, the magnitude of $\Delta \mathrm{E}$ gives no information on the character of the color of the specimen because it does not indicate the quantity and direction of the CIE L*a*b* components. ${ }^{39,40}$ A color difference of $2 \Delta \mathrm{E}$ units has been described as an acceptable clinical shade match in dentistry, whereas color differences above $3.5 \Delta \mathrm{E}$ units are considered unacceptable and are visually detectable. ${ }^{28}$ The ultimate goal in achieving an accurate color match is to achieve $\Delta \mathrm{E}$ values lowest possible.

The objectives of this study were to determine the effects of different surface finishing protocols on the surface roughness, color change and translucency of all-ceramic and metalceramic restorations. Null hypothesis was that the different surface finishing protocols applied on different ceramic systems would not affect their roughness, translucency, and color parameters. 


\section{MATERIAL AND METHODS}

\section{Specimen preparation}

The core and veneering materials used in the experiments are listed in Table I. All veenering ceramics were fabricated in A2 shade without internal or external staining. Disc specimens (core + veneering ceramic or metal + veneering ceramic) of $1.5 \mathrm{~mm}$ thickness and $10 \mathrm{~mm}$ diameter were fabricated (Table I).

In order to fabricate metal-ceramic specimens, the wax patterns were sprued and invested with a phosphate-bonded investment (Alpha Cast Vario; Schutz Dental Group, Rosbach, Germany) and cast using a base metal alloy (Shera Alloy-E; Shera WerkstoffTechnologie, Lemförde, Germany). The final thickness of the metal specimens was adjusted to $0.5 \mathrm{~mm}$ using 600-grit silicon carbide ( $\mathrm{SiC}$ ) abrasive paper (Struers, Willich, Germany). An opaque layer and dentin ceramic (VMK 95 Vita Zahnfabrik, Bad Säckingen, Germany) were consecutively fired on the metal according to the manufacturer's instructions. Two dentin firing cycles were performed. The final thickness of metal-ceramic specimens was adjusted to $1.5 \mathrm{~mm}$ using $\mathrm{SiC}$ abrasive papers (Struers $\mathrm{GmbH})$.

Yttrium-stabilized zirconium dioxide specimens were obtained by milling dry-pressed blocks (Whitepeaks Copran; Whitepeaks Dental Systems, Essen, Germany) with a CAD/CAM system (DCS Precident milling system; DCS Dental AG, Allschwil, Switzerland). The specimens were sintered at $1500^{\circ} \mathrm{C}$ for 7 hours in a high temperature sintering furnace (Keramikofen 1500, Zirkonzahn, Bruneck, Italy). The final thickness $(0.5 \mathrm{~mm})$ of each specimen was adjusted with polishing device (AM Technology, Gyeonggi-Do, Korea) using 600-grit SiC paper (Struers). To produce glass ceramic specimens (IPS e-max Press, Ivoclar Vivadent, Schaan, Liechtenstein), disc-shaped wax patterns were invested with an investment material (IPS Empress Esthetic Speed Investment; Ivoclar Vivadent). Upon burnout, IPS emax Press ingots (MO1 shade; Ivoclar Vivadent) were heat-pressed. The pressed cylinders 
were bench-cooled, divested by $50-\mu \mathrm{m}$ aluminum oxide at 2 bar pressure, and ultrasonically cleaned (Invex liquid; Ivoclar Vivadent) for $10 \mathrm{~min}$. The final thickness $(0.8 \mathrm{~mm})$ of each specimen was adjusted with a polishing device (AM Technology) using 600-grit SiC paper (Struers).

Aluminum oxide core disc specimens $(0.5 \mathrm{~mm} \times 10 \mathrm{~mm})$ were fabricated using a custom-made plastic mold. The mold was filled with alumina gel (Turkom-Cera Alumina Gel; Turkom-Ceramic (M) Sdn. Bhd., Puchong, Selangor, Malaysia). Disc-shaped specimens were removed from the mold after the gel was completely dry, and the specimens were fired in a vacuum furnace (Programat P300; Ivoclar Vivadent) (temperature increase rate, $50^{\circ} \mathrm{C} / \mathrm{min}$; holding temperature, $1150^{\circ} \mathrm{C}$; holding time, 5 minutes). The sintered specimens were hardened using crystal powder (Turkom-Cera Crystal Powder; Turkom-Ceramic (M) Sdn. Bhd.) The crystal powder was mixed with water and applied on the sintered specimens in the same furnace for 30 minutes at $1150^{\circ} \mathrm{C}$. The excess crystals were removed using a laboratory handpiece with a diamond bur at low speed.

Veneering ceramics were applied onto each specimen using a vinyl polysiloxane mould (Exaflex; GC Corp, Tokyo, Japan) backed with a platinum foil. After condensation of the veneering ceramics, the mould was removed, and the test specimens on the platinum foil were transferred to a firing tray to be fired in a ceramic furnace (Programat P90; Ivoclar Vivadent) according to the manufacturers' instructions. All specimens were adjusted to $1.5 \pm$ $0.01 \mathrm{~mm}$ thickness using 600-grit $\mathrm{SiC}$ paper (Struers $\mathrm{GmbH}$ ) and the thickness of the specimens were confirmed with a digital caliper (Youfound Precision Co. Ltd, Zhejiang, China).

Four experimental groups were formed; three core-veneer asemblies $\left(\mathrm{Al}_{2} \mathrm{O}_{3}+\right.$ veneering ceramic-ALV; $\mathrm{ZrO}_{2}+$ veneering ceramic-ZRV; Group 3: $\mathrm{SiO}_{2}-\mathrm{Li}_{2} \mathrm{O}+$ veneering ceramic-LITV) and one metal-ceramic (MC) system consisted of 128 specimens ( $\mathrm{n}=32$ for each group). Each 
group was further randomly divided into 4 subgroups ( $\mathrm{n}=8$ for each subgroup) and subjected to 4 different surface finishing protocols.

Ceramic surface finishing protocols

After ultrasonic cleaning, the ceramic surfaces in each group were finished one of the following four protocols:

1. Air-borne particle abrasion (AB): Specimen surfaces were air-abraded with $50-\mu \mathrm{m}$ aluminum oxide at 2 bar pressure from a distance of approximately $10 \mathrm{~mm}$.

2. Polishing with adjustment kit (PK): Specimen surfaces were polished with a polishing kit (Ceramaster Finishing \& Polishing Kit; Shofu Inc., Kyoto, Japan) using a slow-speed handpiece rotating at approximately $10000 \mathrm{rpm}$, as recommended by the manufacturer. Polishing was performed by the same operator. The adjustment kit consisted of a 4-step protocol: a white stone bur and 3 different polishing burs were used, one at a time, for 20 seconds. Then the polishing wheel was used for 20 seconds. The polishing stick and the polishing paste were directly placed onto the specimen surface and polished using a rubber cup (One Gloss; Shofu Dental GmbH, Ratingen, Germany) for 20 seconds.

3. Polishing with adjustment kit + diamond polishing paste (DP): Specimen surfaces were polished with a polishing kit (Ceramaster Finishing \& Polishing Kit; Shofu Inc.) according to the same procedures described above and further polished with a polishing paste (Ultra II Polishing Paste; PN 0550, Shofu Inc.) using a rubber cup (One Gloss; Shofu Dental GmbH, Ratingen, Germany) for 20 seconds. Polishing paste was directly placed onto the specimen surface.

4. Autoglazing (AG): Specimens were autoglazed by heating at $621^{\circ} \mathrm{C}$ for $3 \mathrm{~min}$ followed by a temperature increase of $83^{\circ} \mathrm{C} / \mathrm{min}$ up to $918^{\circ} \mathrm{C}$ for 30 seconds. 


\section{Surface roughness measurement}

After cleaning specimens ultrasonically in distilled water, surface roughness (Ra) was measured using a profilometer (Surftest SJ 201; Mitutoyo Corp., Tokyo, Japan). Upon calibration, a pick-up with a stylus tip radius of $5 \mu \mathrm{m}$ was used under a constant measuring force of $3 \mathrm{mN}$ with a travel speed of $0.25 \mathrm{~mm}-\mathrm{s}^{-1}$.

\section{Color measurement}

The color coordinates of the specimens in each subgroup $(n=8)$ were measured with an intra-oral spectrophotometer (VITA EasyShade; VITA Zahnfabrik) having separate receiver elements located at different distances from the light source to measure the color of the specimen at different depths. ${ }^{29,37}$ The CIELAB values $\left(L^{*}, a^{*}, b^{*}\right)$ of each specimen was measured 3 times consecutively at the center of the disc with a white background. ${ }^{22}$

Color differences $(\Delta \mathrm{E})$ were calculated according to the following equation: ${ }^{6}$

$\Delta E=\left[\left(\Delta L^{*}\right)^{2}+\left(\Delta a^{*}\right)^{2}+\left(\Delta b^{*}\right)^{2}\right]^{1 / 2}$

The quantitative $\Delta \mathrm{E}$ values between the specimens of Vita A2 shade (VITA Zahnfabrik) (C) and the experimental groups (E) were calculated using the following equation:

$\Delta E=\left[\left(L_{e}^{*}-L_{c}^{*}\right)^{2}+\left(a_{e}^{*}-a_{c}^{*}\right)^{2}+\left(b_{e}^{*}-b^{*}{ }_{c}\right)^{2}\right]^{1 / 2}$

where $\left(L^{*}{ }_{E}-L^{*}\right),\left(a^{*}{ }_{E}-a^{*}\right)$, and $\left(b^{*}{ }_{E}-b^{*}{ }_{C}\right)$ are the differences in $\Delta \mathrm{L}^{*}, \Delta \mathrm{a}^{*}$, and $\Delta \mathrm{b}^{*}$ values, subscript E represents the value obtained from different surface finishing protocols, and subscript $\mathrm{C}$ represents the mean value obtained from color measurements from Vita $\mathrm{A} 2$ shade (VITA Zahnfabrik). $\Delta \mathrm{E}$ values smaller than 0.5 were rated as perfect, $0.5-1$ as excellent, 1-2 as good, 2-3.5 as clinically acceptable, and above 3.5 as clinically-discernable mismatch. ${ }^{28}$ Two colors were judged to be matched when $\Delta \mathrm{E}<1 .^{22} \Delta \mathrm{E}$ value of 1.6 was determined to be a color difference that could not be detected by the human eye. ${ }^{31}$

Color parameters of ceramic specimens were measured against white (CIE L* $=94.467$, $\mathrm{a}^{*}=0.328$, and $\left.\mathrm{b}^{*}=1.425\right)$ and black (CIE $\mathrm{L}^{*}=9.657, \mathrm{a}^{*}=0.523$, and $\left.\mathrm{b}^{*}=-0.075\right)$ backgrounds. 
TP was calculated as TP $=\left[\left(\mathrm{L}_{\mathrm{b}}^{*}-\mathrm{L}_{\mathrm{W}}\right)^{2}+\left(\mathrm{a}_{\mathrm{b}}{ }^{*}-\mathrm{a}_{\mathrm{w}}\right)^{2}+\left(\mathrm{b}_{\mathrm{b}}{ }_{\mathrm{b}}-\mathrm{b}_{\mathrm{W}}\right)^{2}\right]^{1 / 2}$, where the subscript $\mathrm{B}$ refers to the color coordinates over a black background and subscript $\mathrm{W}$ refers to those over a white background. ${ }^{14,18,23}$

Statistical analysis

Statistical analysis was performed using SPSS 17.0 System for Windows (Chicago, IL, USA). The means of each group were analysed by one-way Analysis of Variance (ANOVA) with Bonferroni corrections and Dunnett T3 post-hoc tests to determine the significant differences among ceramic systems after surface finishing protocols in terms of roughness, translucency parameter and color differences $(\alpha=0.05)$. In addition, power calculation was performed using Bonferroni corrected two-sample t-test to detect a significant relevant difference between groups for each parameter.

\section{RESULTS}

Based on a 1:1 ratio between groups, a sample size of 8 was found to reveal more than $90 \%$ power for $\mathrm{Ra}, \Delta \mathrm{E}$ and $\mathrm{TP}$ at $\mathrm{p}<0.05$ significance level.

Surface roughness $(R a)$

The highest mean Ra values were measured in the AB method and the lowest in the AG method (Table II). The differences between $A B$ and the other surface finishing protocols were significant for ALV group $(P=.00)$. The differences between the AG method and the other methods were significant for ZRV group $(P=.00)$. The outcome of $\mathrm{AB}$ and $\mathrm{AG}$ methods were significantly different in LITV specimens $(P=.04)$. For the MC group, the differences between the AG method with both PK $(P=.03)$ and $\mathrm{AB}(P=.00)$ and the DP method with both PK $(P=.01)$ and SB were significant $(P=.00)$ (Table II).

Comparative assessments on the outcome of surface finishing protocols showed that $\mathrm{AB}$ method resulted in the highest $\mathrm{Ra}$ in $\mathrm{ALV}$ and lowest in ZRV $(P=.00)$. While the 
difference between $\mathrm{ALV}$ and $\mathrm{MC}$ were significant in the $\mathrm{PK}$ method $(P=.004)$, mean $\mathrm{Ra}$ values of LITV were higher than other ceramic systems in the AG method. In the DP method, the Ra of ALV and MC was significantly higher than other groups ( $P=.01)$ (Table II).

\section{Color Differences $(\Delta E)$}

Surface finishing protocols significantly affected the $\Delta \mathrm{E}$ values $(P<.05)$ (Table III). The $\triangle \mathrm{E}$ values after $\mathrm{AB}$ and $\mathrm{AG}$ finishing methods in ALV was significantly lower than PK and DP methods $(P<.05)$. Different surface finishing methods did not cause a significant $\Delta \mathrm{E}$ difference in $\mathrm{ZRV}(P>.05)$. The $\triangle \mathrm{E}$ after $\mathrm{AG}$ method was significantly lower than $\mathrm{AB}$ method in LITV $(P=.002)$. The lowest $\Delta \mathrm{E}$ was achieved by DP method in MC specimens that was significantly different from $\mathrm{AB}$ and $\mathrm{AG}$ methods $(P(A G)=.001, P(S B)=.042)$.

After $\mathrm{AB}$ method, $\triangle \mathrm{E}$ of LITV specimens were significantly lower than $\operatorname{ALV}(P=.00)$ and $\mathrm{MC}(P=.002)$ groups. $\triangle \mathrm{E}$ of ALV was significantly higher than the other groups after the DP and PK methods. After AG method, $\Delta \mathrm{E}$ of Group ZRV $(P=.00)$ and Group LITV $(P=.00)$ were significantly lower than Group ALV and MC.

\section{Translucency Parameters (TP)}

$\mathrm{AG}$ and $\mathrm{AB}$ methods showed significant differences between $\mathrm{PK}(P(\mathrm{AG})=.002$, $P(\mathrm{AB})=.001)$ and $\mathrm{DP}(P(\mathrm{AG})=.004, P(\mathrm{SB})=.001)$ methods in ALV (Table IV). In the same group, there were no significant difference between the TP values of $A G$ and $A B$ methods $(P>.05)$, and the TP values of PK and DP methods were also statistically similar to each other $(P>.05)$.

In the $\mathrm{AB}$ method, $\mathrm{TP}$ of ceramic specimens were statistically similar to each other $(P>.05)$ but higher than that of MC specimens $(P<.05)$. In the $\mathrm{PK}$ method, TP of MC specimens was significantly lower than that of all ceramic specimens $(P<.05)$ and TP of ALV was higher than that of ZRV $(P=.003)$. In the DP method, the highest TP was observed in the 
LITV specimens, which was higher than that of ZRV specimens and Group MC specimens $(P<.05)$. Likewise, the highest TP was observed in the LITV specimens and lowest in the MC specimens in the AG method $(P<.05)$. TP of ALV and MC specimens were significantly lower than that of ZRV and LITV in the AG method $(P<.05)$ (Table IV).

\section{DISCUSSION}

Based on the results of this study, the null hypothesis that different surface finishing protocols on different ceramic systems would not be effective on their roughness, translucency, and color parameters could be rejected.

In this study, the specimens of core ceramics were fabricated in the required minimum thicknesses recommended by a previous $\operatorname{study}^{32}$ and according to the manufacturers' recommendations. The color and translucency measured directly on a coping could be of greater clinical relevance when compared to measurements performed on specimens with standard geometries. ${ }^{17,30}$ However, the effects of the variables related to the production process for a ceramic restoration, such as grinding, sintering, finishing, and definitive core and veneering thicknesses could be incorporated in the disc specimens. For this reason disc specimens were used in this study.

In the present study, while the smoothest surface was obtained with AG method in all groups, AB method showed the highest Ra values in all groups. After finishing with PK or DP methods, acceptable Ra values were re-established. Specimens that were subjected to DP method displayed lower Ra values than that of PK method. PK or DP methods created Ra comparable to that of the glazed specimens, which is in line with previous observations. ${ }^{4,8,10}$ Various finishing and polishing protocols could be employed on ceramic surfaces to preserve the structural resistance and obtain a clinically acceptable smoothness compared with glazing. ${ }^{4,6,8-10}$ In this context, it seems that diamond pastes are efficient in decreasing the 
irregularities on ceramics, when used after the adjustment burs. ${ }^{6}$ Diamond polishing pastes should have a fine particle size to enable surface polishing, but should be rough enough to be effective when used for ceramic restorations. ${ }^{4,6}$ The Ra findings of this study suggests that clinical polishing of rough ceramic surfaces with PK or DP methods could be a safe and quick alternative to glazing procedures.

Possible sources of processing variables in porcelain firing include thickness and color of the opaque; thickness, color, and translucency of the body and enamel layers; firing temperature; and number of firings. $.^{22,25,26,28,30} \Delta \mathrm{E}>3.5$ has been accepted as a clinically unacceptable color difference..$^{28,35,36}$ The aim of this study was not to achieve the shade match but to evaluate the $\Delta \mathrm{E}$ values in comparison with the corresponding VITA shade tab (A2) considering the limitations of the specimen preparation protocols used in this study. Almost all $\Delta \mathrm{E}$ values were higher than 3.5, except for LITV ceramic system $(3.05 \pm 0.60)$ subjected to the AG method. Dentin ceramic of lithium disilicate ceramic contains nanofluorapatite crystals that ensure the color, surface texture, and translucency match with that of natural tooth. The different-sized fluorapatite crystals control the relationship between translucency, opalescence, and brightness of the restorations. ${ }^{24}$ Results of the current study indicated perceptible color changes for the tested ceramic systems subjected to a different surface finishing protocols when compared with Vita shade tab. However, in this study, only the dentin ceramic was used as a layering ceramic in each ceramic system. No additional enamel ceramic, external and internal staining was used. Thus, the great shade mismatch of the resultant color of the specimens with the VITA A2 shade tab could be attributed to this factor. Especially in ALV group, the highest $\triangle \mathrm{E}$ values were obtained. This would be due to the opaque structure of the alumina material. No additional intermediate layer such as opaque ceramic layers or liners were applied onto core ceramics, in order not to add a new parameter to the present ones. 
Stavridakis et $\mathrm{al}^{28}$ proposed that teeth with low value and high translucency might be considered to be the closest to natural teeth and therefore, should be restored with Empress, In-Ceram Spinell, or Empress 2. On the other hand, Kelly et $\mathrm{al}^{15}$ stated that opaque teeth with high value could be restored with opaque substrates such as In-Ceram Alumina or metalceramic restorations. Heffernan et $\mathrm{al}^{16}$ indicated that In-Ceram Zirconia would also be feasible because its opacity is similar to that of the metal-ceramic systems. In addition, Baldispara et $\mathrm{al}^{17}$ reported that the tranclucency of zirconia copings was significantly lower than that of lithium disilicate glass-ceramic controls. The results of this study were partially in accordance with the results of previous observations since the different surface finishing protocols resulted in variations in the TP values of different ceramic systems. Zirconia-based specimens showed significantly lower TP values than lithium disilicate-based specimens after subjecting them to DP method but exhibited statistically similar values after finishing with PK and AG methods. MC specimens showed lower TP values than the other groups in the present study. Therefore, MC may not be needed by the background colours. ${ }^{27}$ For different finishing methods applied on ceramics, there were no significant differences in TP values within the same group, except for ALV. The TP values of ALV specimens subjected to PK and DP methods were significantly higher than that of $\mathrm{AB}$ and AG methods. The TP values may be affected by the structure of the veneering ceramic varying in crystalline contents, increased specimen thickness, reflectance at the interface between core and veneering ceramic, porosity between the layers, and any changes in the constituent core material with additional firing cycles. ${ }^{32}$ Although the TP value change was not expected after different surface finishing methods in ALV specimens, and the results were in contrast to some studies, ${ }^{25,32}$ the structure of its veneering porcelain may have affected the results. Alghazzawi et al ${ }^{40}$ stated that modifying the veneering ceramic can optimize the color of an esthetic restoration. Further studies are needed to test the effect of different surface finishing protocols on color and TP of 
different alumina-based ceramic restorations using veneering ceramics other than the one used in this study.

The surface finishing protocols applied for the $\mathrm{Si}_{2} \mathrm{O}-\mathrm{Li}_{2} \mathrm{O}$ ceramic systems and the parameters $(\mathrm{Ra}, \Delta \mathrm{E}, \mathrm{TP})$ evaluated in this study showed statistically significant differences. However, when the methods were compared, the smoothest surfaces and the lowest $\Delta \mathrm{E}$ values were seen in the AG method, and the highest TP values were obtained in DP method. Therefore, to accomplish the most natural outcomes, the AG and DP methods can be used for this ceramic system. The finishing methods applied for the $\mathrm{ZrO}_{2}$ ceramic system resulted in comparable outcomes when all parameters $(\mathrm{Ra}, \Delta \mathrm{E}, \mathrm{TP})$ are considered. When the methods were compared, however, the smoothest surfaces, lowest $\Delta \mathrm{E}$ values and highest TP values were obtained in the AG method, followed by DP and PK. Giving priority to AG and DP methods all finishing methods can be performed on this ceramic. The finishing methods applied for ALV ceramic system and the $\triangle \mathrm{E}$ and TP parameters displayed drastic differences between $\mathrm{AG}$ and the other methods. As the smoothest surface, the lowest $\Delta \mathrm{E}$ values and the highest TP values were obtained with the AG method, this method might be considered as the most suitable method to achieve a stable restoration surface. The finishing protocols applied for the $\mathrm{MC}$ system and the Ra and $\triangle \mathrm{E}$ parameters evaluated, revealed significant differences between AG and the other methods. The lowest mean Ra value was obtained in the AG method. However, the highest $\Delta \mathrm{E}$ was also observed in $\mathrm{AG}$ method and the lowest in the DP method. These findings might suggest the use of DP and PK methods for the production of a natural appearing metal-ceramic restoration.

In vitro studies on ceramic translucency and color may be limited due to a lack of clear clinical relevance. ${ }^{17}$ Even if the research designs generally allow for determining optical properties, the conversion of these data in terms of clinical outcomes poses great difficulty. 


\section{CONCLUSIONS}

Within the limitations of this study, the following conclusions were drawn:

1. For all ceramic types, the smoothest surfaces were obtained after autoglazing.

2. The resultant color of fabricated all-ceramic restorations can hardly match the target color of the traditional shade guide.

3. Surface finishing protocols significantly affect the translucency in alumina-based ceramics and also slightly change the translucency in zirconia-based and lithium disilicate-based ceramics.

4. For accomplishing natural looking restorations with various core ceramics and metal frameworks veneered with feldspathic ceramic for less color change and high translucency, different surface finishing protocols should be used. 


\section{REFERENCES}

1. Bell AM, Kurzeja R, Gamberg MG. Ceramometal crowns and bridges. Focus on failures. Dent Clin North Am 1985;29:763-78.

2. Seghi RR, Johnston WM, O'Brien WJ. Spectrophotometric analysis of color differences between porcelain systems. J Prosthet Dent 1986;56;35-40.

3. Jagger DC, Harrison A. An in vitro investigation into the wear effects of unglazed, glazed and polished porcelain on human enamel. J Prosthet Dent 1994;72:320-3.

4. Al-Wahadni AM, Martin DM. An in vitro investigation into the wear effects of glazed, unglazed and refinishing dental porcelain on an opposing material. J Oral Rehabil1999;26:538-46.

5. Wiley MG. Effects of porcelain on occluding surface of restored teeth. J Prosthet Dent $1989 ; 61: 133-7$

6. Sarac D, Sarac YS, Yuzbasioglu E, Bal S. The effects of porcelain polishing systems on the color and surface texture of feldspathic porcelain. J Prosthet Dent 2006;96:1228.

7. Wang H, Xiong F, Zhenhua L. Influence of varied surface texture of dentin porcelain on optical properties of porcelain specimens. J Prosthet Dent 2011;105:242-8.

8. Ancowitz S, Torres T, Rostami H. Texturing and polishing: The final attempt at value control. Dent Clin North Am 1998;42:607-12.

9. Camacho GB, Vinha D, Panzeri H, Nonaka T, Gonçalves M. Surface roughness of a dental ceramic after polishing with different vehicles and diamond pastes. Braz Dent $\mathbf{J}$ 2006;17:191-4.

10. Tholt de Vasconcellos B, Miranda-Junior WG, Prioli R, Thompson J, Oda M. Surface roughness in ceramic with different finishing techniques using atomic force microscope and profilometer. Oper Dent 2006;31:442-9. 
11. Brodbelt RH, O'Brien WJ, Fan PL. Translucency of dental porcelains. J Dent Res 1980;59:70-5.

12. O'Keefe K1, Pease PL, Herrin HK. Variables affecting the spectural transmittance of light through porcelain veneer samples. J Prosthet Dent 1991;66:434-8.

13. Watts DC, Cash AJ. Analysis of optical transmission by $400-500 \mathrm{~nm}$ visible light into aesthetic dental biomaterials. J Dent 1994;22:112-7.

14. Johnston WM, Ma T, Kienle BH. Translucency parameter of colorants for maxillofacial prostheses. Int J Prosthodont 1995;8:79-86.

15. Kelly JR, Nishimura I, Campbell SD. Ceramics in dentistry: historical roots and current perspectives. J Prosthet Dent 1996;75:18-32.

16. Heffernan MJ, Aquilino SA, Diaz Arnold AM, Haselton DR, Stanford CM, Vargas MA. Relative translucency of six all-ceramic systems. Part I: Core materials. J Prosthet Dent 2002;88:4-9.

17. Baldissara P, Llukacej A, Ciocca L, Valandro FL, Scotti R. Translucency of zirconia copings made with different CAD/CAM systems. J Prosthet Dent 2010;104:6-12.

18. Lim HN, Yu B, Lee YK. Spectroradiometric and spectrophotometric translucency of ceramic materials. J Prosthet Dent 2010;104:239-46.

19. Lee YK. Changes in the translucency of porcelain and repairing resin composite by the illumination. Dent Mater 2007;23: 492-7.

20. McLean JW. New dental ceramics and esthetics. J Esthet Dent 1995;7:141-9.

21. Cho MS, Lee YK, Lim BS, Lim YJ. Changes in optical properties of enamel porcelain after repeated external staining. J Prosthet Dent 2006;95:437-43.

22. Shokry TE, Shen C, Elhosary MM, Elkhodary AM. Effect of core and veneer thicknesses on the color parameters of two all-ceramic systems. J Prosthet Dent 2006;95:124-9. 
23. Ilie N, Hickel R. Correlation between ceramic translucency and polymerization efficiency through ceramics. Dent Mater 2008;24:908-14.

24. Luo XP, Zhang L. Effect of veneering techniques on color and translucency of Y-TZP. J Prosthodont 2010;19:465-70.

25. Sahin V, Uludag B, Usumez A, Ozkir SE. The effect of repeated firings on the color of an alumina ceramic system with two different veneering porcelain shades. J Prosthet Dent 2010;104:372-8.

26. Paniz G, Kim Y, Abualsaud H, Hirayama H. Influence of framework design on the cervical color of metal ceramic crowns. J Prosthet Dent 2011;106:310-8.

27. Terada Y, Sakai T, Hirayasu R. The masking ability of an opaque porcelain: a spectrophotometric study. Int J Prosthodont 1989;2:259-64.

28. Stavridakis MM, Papazoglou E, Seghi RR, Johnston WM, Brantley WA. Effect of different high-palladium metal-ceramic alloys on the color of opaque and dentin porcelain J Prosthet Dent 2004;92:170-8.

29. Charisis D, Koutayas SO, Kamposiora P, Doukoudakis. Spectrometric evaluation of the influence of different backgrounds on the color of glass-infiltrated ceramic veneers. Eur J Esthet Dent 2006;1:142-56.

30. Lee YK, Cha HS, Ahn JS. Layered color of all-ceramic core and veneer ceramics. J Prosthet Dent 2007;97:279-86.

31. Ishikawa-Nagai S, Yoshida A, Sakai M, Kristiansen J, Da Silva JD. Clinical evaluation of perceptibility of color differences between natural teeth and all-ceramic crowns. J Dent 2009;37s:e57-e63.

32. Heffernan MJ, Aquilino SA, Diaz Arnold AM, Haselton DR, Stanford CM, Vargas MA. Relative translucency of six all-ceramic systems. Part II: Core and veneer materials. J Prosthet Dent 2002;88:10-5. 
33. Nakamura T, Saito O, Fuyikawa J, Ishigaki S. Influence of abutment substrate and ceramic thickness on the colour of heat-pressed ceramic crowns. J Oral Rehabil 2002;29:805-9.

34. Johnston WM, Kao EC. Assessment of appearance match by visual observation and clinical colorimetry. J Dent Res 1989;68:819-22.

35. Caglar A, Yamanel K, Gulsahi K, Bagis B, Özcan M. Could digital imaging be an alternative for digital colorimeters? Clin Oral Investig 2010;14:713-8.

36. Yamanel K, Caglar A, Özcan M, Gulsah K, Bagis B. Assessment of color parameters of composite resin shade guides using digital imaging versus colorimeter. J Esthet Restor Dent 201;22:379-88.

37. CIE 1971: International Commission on Illumination. Colorimetry: Official Recommendations of the International Commission on Illumination. Publication CIE No. 15 (E-1.3.1), Bureau Central de la CIE, Paris; 1971.

38. Baltzer A, Kaufmann-Jinoian V. Shading of ceramic crowns using digital tooth shade matching devices. Int J Comput Dent 2005;8:129-52.

39. Sproull RC. Color matching in dentistry. Part I. The three-dimensional nature of color. 1973. J Prosthet Dent 2001;86:453-7.

40. Alghazzawi TF, Lemons J, Liu PR, Essig ME, Janowski GM. Evaluation of the optical properties of CAD-CAM generated yttria-stabilized zirconia and glass-ceramic laminate veneers. J Prosthet Dent 2012;107:300-8. 


\section{Tables}

Table I. Information on the core and veneering materials used in the study.

Table II. The mean ( \pm standard deviations) of Ra values $(\mu \mathrm{m})$ for ceramic systems after various surface finishing protocols. Different upper case letters represent statistically significant differences within each row. Different upper case numbers represent statistically significant differences within each column $(\alpha=0.05)$.

Table III. The mean ( \pm standard deviations) of color differences $(\Delta \mathrm{E})$ for ceramic systems after various surface finishing protocols. Different upper case letters represent statistically significant differences within each row. Different upper case numbers represent statistically significant differences within each column $(\alpha=0.05)$.

Table IV. The mean ( \pm standard deviations) of translucency parameters for ceramic systems after various surface finishing protocols. Different upper case letters represent statistically significant differences within each row. Different upper case numbers represent statistically significant differences within each column $(\alpha=0.05)$. 
Table I. Information on the core and veneering materials used in the study.

\begin{tabular}{|c|c|c|c|c|c|c|}
\hline Material & Code & $\begin{array}{c}\text { Main } \\
\text { composition }\end{array}$ & $\begin{array}{l}\text { Batch } \\
\text { No. }\end{array}$ & $\begin{array}{l}\text { Thickness } \\
\text { (mm) }\end{array}$ & Manufacturer & $\begin{array}{l}\text { Veneer } \\
\text { Ceramic }\end{array}$ \\
\hline $\begin{array}{l}\text { Alumina Blank } \\
\text { Turkom-Cera } \\
\text { crystal powder }\end{array}$ & ALV & $\mathrm{Al}_{2} \mathrm{O}_{3}$ & AB00640 & 0.5 & $\begin{array}{c}\text { Turkom-Ceramic (M) } \\
\text { Sdn. Bhd., Kuala } \\
\text { Lumpur, Malaysia }\end{array}$ & $\begin{array}{c}\text { Shofu Ceramage } \\
\text { dentin body }\end{array}$ \\
\hline Whitepeaks Copran & ZRV & $\mathrm{ZrO}_{2}$ & $\begin{array}{l}560002 \\
1.2510\end{array}$ & 0.5 & $\begin{array}{l}\text { Whitepeaks Dental } \\
\text { Systems GmbH \& } \\
\text { Co., Essen, } \\
\text { Germany }\end{array}$ & $\begin{array}{l}\text { Cerabien ZR } \\
\text { dentin }\end{array}$ \\
\hline $\begin{array}{l}\text { IPS e.max Press } \\
\text { ingots MO1 } \\
\text { (for use } 110-140, \\
\text { A1, A2, B1, B2) }\end{array}$ & LITV & $\mathrm{SiO}_{2}-\mathrm{Li}_{2} \mathrm{O}$ & $\mathrm{J} 22317$ & 0.8 & $\begin{array}{l}\text { Ivoclar Vivadent, } \\
\text { Schaan, Liechtenstein }\end{array}$ & $\begin{array}{l}\text { IPS e.max Ceram } \\
\text { dentin/body }\end{array}$ \\
\hline $\begin{array}{l}\text { Shera } \\
\text { Alloy-E }\end{array}$ & $\mathrm{MC}$ & $\begin{array}{l}\text { Non- } \\
\text { precious } \\
\text { bonding } \\
\text { alloy }\end{array}$ & 91192 & 0.5 & $\begin{array}{c}\text { Shera Werkstoff- } \\
\text { Technologie GmbH } \\
\text { \& Co. KG, } \\
\text { Lemförde, Germany }\end{array}$ & $\begin{array}{l}\text { VMK95 } \\
\text { Metal-ceramic } \\
\text { dentin }\end{array}$ \\
\hline
\end{tabular}

Table II. The results of univariate ANOVA with dependent variable surface roughness

(Ra).

\begin{tabular}{|llllll|}
\hline Source of variation & DF & $\begin{array}{l}\text { Type II } \\
\text { Sum of }\end{array}$ & MS & F & P \\
Square & & & \\
\hline $\begin{array}{l}\text { Core+veneering } \\
\text { material }\end{array}$ & 3 & 17.004 & 5.668 & 18.513 & 0.000 \\
\hline
\end{tabular}




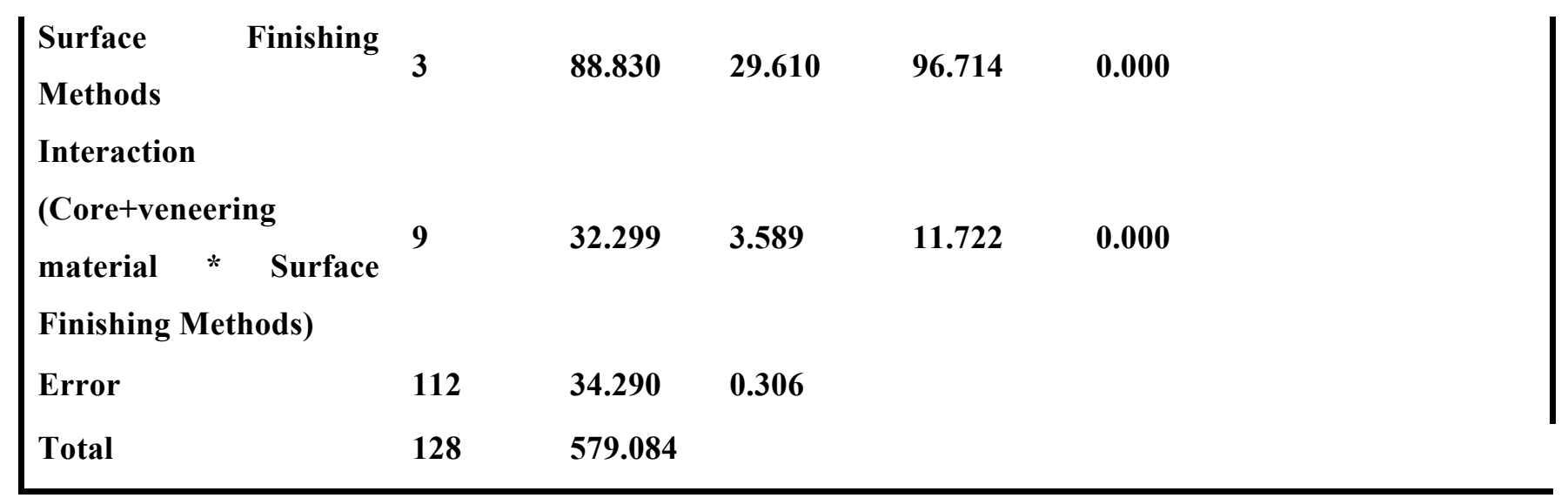

Table III. The mean ( \pm standard deviations) of Ra values $(\mu \mathrm{m})$ for ceramic systems after various surface finishing protocols.

\begin{tabular}{|c|c|c|c|c|}
\hline $\begin{array}{l}\text { Material Type and } \\
\text { Group }\end{array}$ & $\begin{array}{l}\text { Air-abrasion } \\
\quad \text { (AB) }\end{array}$ & $\begin{array}{l}\text { Polishing with } \\
\text { adjustment kit } \\
\text { (PK) }\end{array}$ & $\begin{array}{l}\text { Polishing with } \\
\text { adjusment } \\
\text { kit+polishing } \\
\text { paste (DP) }\end{array}$ & $\begin{array}{l}\text { Autoglazing } \\
\text { (AG) }\end{array}$ \\
\hline $\begin{array}{l}\mathrm{Al}_{2} \mathrm{O}_{3}+\text { veneering } \\
\text { ceramic } \\
(\mathrm{ALV})\end{array}$ & $4.27(0.70)^{1}$ & $1.32(0.66)^{2}$ & $1.14(0.23)^{2}$ & $0.98(0.21)^{2}$ \\
\hline $\begin{array}{l}\mathrm{ZrO}_{2}+\text { veneering } \\
\text { ceramic } \\
(\mathrm{ZRV})\end{array}$ & $2.14(0.85)^{1}$ & $1.94(0.09)^{2}$ & $1.68(0.29)^{1}$ & $0.77(0.23)^{2}$ \\
\hline $\begin{array}{l}\mathrm{SiO}_{2}-\mathrm{Li}_{2} \mathrm{O}+ \\
\text { veneering ceramic } \\
\text { (LITV) }\end{array}$ & $2.98(1.12)^{1}$ & $1.82(0.16)^{2}$ & $1.73(0.52)^{2}$ & $1.45(0.42)^{2}$ \\
\hline $\begin{array}{l}\text { Metal-ceramic } \\
\text { (MC) }\end{array}$ & $3.91(0.41)^{1}$ & $2.41(0.90)^{2}$ & $1.14(0.25)^{3}$ & $1.00(0.28)^{2}$ \\
\hline
\end{tabular}

Different upper case numbers represent statistically significant differences within each row $(\alpha=0.05)$. 
Table IV. The results of univariate ANOVA with dependent variable delta $E(\Delta E)$.

\begin{tabular}{|c|c|c|c|c|c|}
\hline Source of variation & DF & $\begin{array}{l}\text { Type II } \\
\text { Sum of } \\
\text { Square }\end{array}$ & MS & $\mathbf{F}$ & $P$ \\
\hline $\begin{array}{l}\text { Core+veneering } \\
\text { material }\end{array}$ & 3 & 586.868 & 195.623 & 103.667 & 0.000 \\
\hline $\begin{array}{l}\text { Surface } \quad \text { Finishing } \\
\text { Methods }\end{array}$ & 3 & 19.198 & 6.399 & 3.391 & 0.021 \\
\hline $\begin{array}{l}\text { Interaction } \\
\text { (Core+veneering } \\
\text { material * Surface } \\
\text { Finishing Methods) }\end{array}$ & 9 & 122.412 & 13.601 & 7.208 & 0.000 \\
\hline Error & 112 & 211.348 & 1.887 & & \\
\hline Total & 128 & 6377.628 & & & \\
\hline
\end{tabular}

Table V. The mean ( \pm standard deviations) of color differences $(\Delta \mathrm{E})$ for ceramic systems after various surface finishing protocols.

\begin{tabular}{|c|c|c|c|c|}
\hline $\begin{array}{c}\text { Material Type and } \\
\text { Group }\end{array}$ & $\begin{array}{l}\text { Air-abrasion } \\
\text { (AB) }\end{array}$ & $\begin{array}{l}\text { Polishing with } \\
\text { adjustment kit } \\
\text { (PK) }\end{array}$ & $\begin{array}{l}\text { Polishing with } \\
\text { adjusment } \\
\text { kit+polishing paste } \\
\text { (DP) }\end{array}$ & $\begin{array}{l}\text { Autoglazing } \\
\text { (AG) }\end{array}$ \\
\hline $\begin{array}{l}\mathrm{Al}_{2} \mathrm{O}_{3}+\text { veneering } \\
\text { ceramic }\end{array}$ & $7.87(0.77)^{3}$ & $10.73(0.74)^{2}$ & $12.13(1.40)^{1}$ & $8.77(0.92)^{3}$ \\
\hline
\end{tabular}




\begin{tabular}{|c|c|c|c|c|}
\hline$(\mathrm{ALV})$ & & & & \\
\hline $\begin{array}{l}\mathrm{ZrO}_{2}+\text { veneering } \\
\text { ceramic } \\
(\mathrm{ZRV})\end{array}$ & $6.68(1.70)^{1}$ & $5.24(2.61)^{1}$ & $5.17(1.79)^{1}$ & $4.47(1.64)^{1}$ \\
\hline $\begin{array}{l}\mathrm{SiO}_{2}-\mathrm{Li}_{2} \mathrm{O}+ \\
\text { veneering ceramic } \\
\text { (LITV) }\end{array}$ & $4.89(0.93)^{1}$ & $3.98(1.34)^{1,2}$ & $4.54(1.49)^{1,2}$ & $3.05(0.60)^{2}$ \\
\hline $\begin{array}{l}\text { Metal-ceramic } \\
\text { (MC) }\end{array}$ & $7.51(1.46)^{1}$ & $6.39(0.84)^{1,2}$ & $5.61(0.90)^{2}$ & $7.16(1.25)^{1,2}$ \\
\hline
\end{tabular}

Different upper case numbers represent statistically significant differences within each row $(\alpha=0.05)$.

Table VI. The results of univariate ANOVA with dependent variable translucency parameter (TP).

\begin{tabular}{|c|c|c|c|c|c|}
\hline Source of variation & DF & $\begin{array}{l}\text { Type II } \\
\text { Sum of } \\
\text { Square }\end{array}$ & MS & $\mathbf{F}$ & $P$ \\
\hline $\begin{array}{l}\text { Core+veneering } \\
\text { material }\end{array}$ & 3 & 1030.186 & 343.395 & 109.835 & 0.000 \\
\hline $\begin{array}{l}\text { Surface } \quad \text { Finishing } \\
\text { Methods }\end{array}$ & 3 & 79.164 & 26.388 & 8.440 & 0.000 \\
\hline $\begin{array}{l}\text { Interaction } \\
(\text { Core+veneering } \\
\text { material * Surface } \\
\text { Finishing Methods) }\end{array}$ & 9 & 116.359 & 12.929 & 4.135 & 0.000 \\
\hline Error & 112 & 350.166 & 3.126 & & \\
\hline Total & 128 & 5983.870 & & & \\
\hline
\end{tabular}


Table VII. The mean ( \pm standard deviations) of translucency parameters for ceramic systems after various surface finishing protocols.

\begin{tabular}{|c|c|c|c|c|}
\hline $\begin{array}{c}\text { Material Type and } \\
\text { Group }\end{array}$ & $\begin{array}{l}\text { Air-abrasion } \\
\quad \text { (AB) }\end{array}$ & $\begin{array}{l}\text { Polishing with } \\
\text { adjustment kit } \\
\text { (PK) }\end{array}$ & $\begin{array}{l}\text { Polishing with } \\
\text { adjusment } \\
\text { kit+polishing paste } \\
\text { (DP) }\end{array}$ & $\begin{array}{l}\text { Autoglazing } \\
\text { (AG) }\end{array}$ \\
\hline $\begin{array}{l}\mathrm{Al}_{2} \mathrm{O}_{3}+\text { veneering } \\
\text { ceramic } \\
(\mathrm{ALV})\end{array}$ & $4.76(0.80)^{1}$ & $8.56(0.68)^{2}$ & $8.90(1.61)^{2}$ & $5.66(1.32)^{1}$ \\
\hline $\begin{array}{l}\mathrm{ZrO}_{2}+\text { veneering } \\
\text { ceramic } \\
(\mathrm{ZRV})\end{array}$ & $5.25(4.54)^{1}$ & $5.59(1.50)^{1}$ & $7.02(1.67)^{1}$ & $8.00(1.46)^{1}$ \\
\hline $\begin{array}{l}\mathrm{SiO}_{2}-\mathrm{Li}_{2} \mathrm{O}+ \\
\text { veneering ceramic } \\
\text { (LITV) }\end{array}$ & $7.94(1.94)^{2}$ & $7.47(2.38)^{2}$ & $10.58(1.71)^{1}$ & $9.31(1.46)^{1,2}$ \\
\hline $\begin{array}{l}\text { Metal-ceramic } \\
\text { (MC) }\end{array}$ & $0.85(0.52)^{2}$ & $1.88(0.84)^{1}$ & $1.16(0.57)^{1,2}$ & $0.87(0.89)^{2}$ \\
\hline
\end{tabular}

Different upper case numbers represent statistically significant differences within each row $(\alpha=0.05)$. 